\section{Effects of Red light on the Growth of Zantedeschia Plantlets in vitro and Tuber Formation Using Light-emitting Diodes}

\author{
Ruey-Chi Jao ${ }^{1}$ \\ Department of Information Management, Chienkuo Technology University
}

Chien-Chou Lai

Department of Bio-Industrial Mechatronics Engineering, National Taiwan University

Wei Fang and Sen-Fuh Chang

Department of Bio-Industrial Mechatronics Engineering, National Taiwan University

Additional index words. LED, Zantedeschia, AC power, red light

\begin{abstract}
Effects of light generated by red and blue light-emitting diodes on the photomixotrophic growth of Zantedeschia jucunda 'Black Magic' plantlets in vitro and tuber formation after transplant under the same PPF and photoperiod were investigated. All five treatments had the same photosynthetic photon flux (PPF, $\left.80 \pm 5 \mu \mathrm{mol} \cdot \mathrm{m}^{-2} \cdot \mathrm{s}^{-1}\right)$ and photoperiod (16 hours daytime/8 hours nighttime), leading to the same daily light integral. Results showed that the tubular fluorescent lamp (TFL) treatment had the highest value on chlorophyll content and dry weight accumulation than other treatments using light-emitting diodes (LEDs). In LED treatments, there were no significant differences on dry weight and growth rate but with significant differences on chlorophyll content and plant height when blue light LEDs were added. It revealed that blue light was involved in plant height and chlorophyll development control mechanism. Results also showed that minor difference in 28 days of transplant production (in vitro) among treatments does not extends after 6 months of tuber formation stage grown in greenhouse. At present, blue LEDs cost much more than that of red LEDs, results of this study suggested that using red LEDs alone and powered with AC is feasible for the commercial production of Zantedeschia plantlets in vitro.
\end{abstract}

Light-emitting diodes(LEDs) are a potential alternative to tubular fluorescent lamps (TFLs) due to their low forward current, small in size, wavelength specific, solid-state construction, low degradation and long life (Brown et al., 1995; Bula et al., 1991; Fang and Jao, 2000). A light source for young plants production using blue (B) and red (R) LEDs was developed with the capabilities of altering blue and/or red light intensity, R to B ratio, frequency and duty ratio of light (Jao and Fang, 2003). Using such a device, authors found that continuous light from LEDs and TFLs had no significant difference to the growth of potato (Solanum tuberosum L. 'Kennebec') plantlets in vitro. However, intermittent or pulse light promotes the growth of potato plantlets significantly (Jao and Fang, 2004a). Concurrent red and blue light enhances growth of potato plantlets compare with alternating red and blue light under the same daily light integral $\left(5.53 \mathrm{~mol} \cdot \mathrm{m}^{-2} \cdot \mathrm{d}^{-1}\right)$ and $16 / 8$-h photoperiod (Jao and Fang, 2004b).

Plant growth and development are affected by light intensity, light quality, duration, and photoperiod (Taiz and Zeiger, 1991). Growth, morphology, and differentiation of in vitro

Received for publication 5 Aug. 2004. Accepted for publication 26 Sept. 2004.

${ }^{1}$ Assistant professor. Corresponding author: e-mail rueychi.jao@msa.hinet.net.

${ }^{2} \mathrm{PhD}$ candidate.

${ }^{3}$ Professor.

Table 1. Summary of five treatments.

${ }^{2}$ Control group using TFL light.
Zantedeschia are commercial available as cut flowers and potted plants. Tissue-culturederived plantlets are an alternative planting material for tuber or cut flowers production in calla lily (Clemens and Welsh, 1993). However, little information is available on how light quality influences the growth of Zantedeschia plantlets in vitro. The focus of this study was to compare effects of light generated by red and blue light-emitting diodes and TFLs (control group) on the photomixotrophic growth of Zantedeschia plantlets during in vitro stage and later tuber formation after transplant into greenhouse under the same PPF and photoperiod.

\section{Materials and Methods}

Plant materials and culture conditions. In vitroplantlets of calla lily (Zantedeschiajucunda 'Black Magic') at final stage were provided by Seed Improvement and Propagation Station (Hsinshe, Taichung, Taiwan) and cultured in 10 $\times$ 10-cm, 785-mL cylindrical poly vinyl chloride (PVC) containers(Yu-Ping Corp., Taiwan). Each vessel contained 20 plantlets. In total, 5 treatments and 100 samples were cultured. Vessels were incubated in a controlled environment at $25 \pm$ $2{ }^{\circ} \mathrm{C}$ and $50 \% \pm 10 \% \mathrm{RH}$. Each treatment was arranged in a completely randomized design of 10 individual samples. In total, 50 samples were used for comparison during in vitro stage. Another 50 samples were transplanted and grown using rockwool (Groden, Denmark) culture with drip lines (Netafim, Isreal) in a pad and fan greenhouse for tuber formation. After 6 months, tuber size (shortest length of diameter) was recorded for each sample. Three size groups were used including $<3 \mathrm{~cm}, 3$ to $5 \mathrm{~cm}$, and $>5 \mathrm{~cm}$. Tubers $>3 \mathrm{~cm}$ are considered marketable. Percentage of each group and marketable size were calculated. Each treatment was conducted three times.

Light treatments. Cultures of in vitro plantlets were illuminated using red and blue LEDs powered by self-designed driver and TFL light. Photoperiod was 16/8 h (day/night) and photosynthetic photon flux (PPF) was 80 $\pm 5 \mu \mathrm{mol} \cdot \mathrm{m}^{-2} \cdot \mathrm{s}^{-1}$. PPF was measured (LI- 1800 ; LI-COR Inc.) when the culture bench was empty. The LED lighting system used was described previously by Jao and Fang (2003, 2004a, 2004b).

Totally, five different light treatments were used in this study (Table 1). Treatment 1 was the control group using TFL. Treatments 2 to 5 used LED as light source. Treatments 2,3, and 5 used red LED alone with different frequency and duty ratio. Treatment 2 used AC power to light

\begin{tabular}{lccccc}
\hline $\begin{array}{l}\text { Treatment } \\
\text { code }\end{array}$ & $\begin{array}{l}\text { Red light PPF } \\
\left(\mu \mathrm{mol} \cdot \mathrm{m}^{-2} \cdot \mathrm{s}^{-1}\right)\end{array}$ & $\begin{array}{c}\text { Blue light PPF } \\
\left(\mu \mathrm{mol} \cdot \mathrm{m}^{-2} \cdot \mathrm{s}^{-1}\right)\end{array}$ & $\begin{array}{c}\text { Frequency } \\
(\mathrm{Hz})\end{array}$ & $\begin{array}{c}\text { Duty ratio } \\
(\%)\end{array}$ & $\begin{array}{c}\text { Driver } \\
\text { used? }\end{array}$ \\
\hline $1^{\mathrm{z}}$ & 48 & 32 & 60 & 50 & $\mathrm{~N}$ \\
$2^{\mathrm{y}}$ & 80 & 0 & 60 & 50 & $\mathrm{~N}$ \\
$3^{\mathrm{x}}$ & 80 & 0 & $\mathrm{~N} / \mathrm{A}$ & 100 & $\mathrm{Y}$ \\
$4^{\mathrm{w}}$ & 48 & 32 & $\mathrm{~N} / \mathrm{A}$ & 100 & $\mathrm{Y}$ \\
$5^{\mathrm{v}}$ & 80 & 0 & 60 & 50 & $\mathrm{Y}$ \\
\hline
\end{tabular}

${ }^{y}$ Red LED light alone using AC power with $60-\mathrm{Hz}$ frequency and $50 \%$ duty ratio.

${ }^{x}$ Red LED light alone using DC power from driver with $100 \%$ duty ratio.

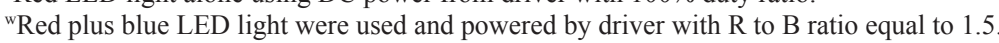

${ }^{v}$ Red LED light alone using DC power from driver with $60-\mathrm{Hz}$ frequency and $50 \%$ duty ratio. 
Table 2. Plant height, chlorophyll content, shoot and root dry and fresh weights per plantlet, percentage of dry matter, and shoot and root dry weight ratio (S to $\mathrm{R}$ ratio) on a dry weight basis of the Zantedeschia plantlets in vitro $28 \mathrm{~d}$ after treatments.

\begin{tabular}{|c|c|c|c|c|c|c|c|c|c|c|}
\hline \multirow[b]{2}{*}{ Treatment } & \multirow{2}{*}{$\begin{array}{l}\text { Plant } \\
\text { ht } \\
(\mathrm{cm})\end{array}$} & \multirow{2}{*}{$\begin{array}{c}\text { Chlorophyll } \\
\text { content } \\
\text { (SPAD) }\end{array}$} & \multicolumn{3}{|c|}{$\begin{array}{c}\text { Fresh wt } \\
\text { (g/plantlet) }\end{array}$} & \multicolumn{3}{|c|}{$\begin{array}{c}\text { Dry wt } \\
\text { (g/plantlet) }\end{array}$} & \multirow{2}{*}{$\begin{array}{c}\text { Dry } \\
\text { matter } \\
(\%)\end{array}$} & \multirow{2}{*}{$\begin{array}{l}\mathrm{S} \text { to } \mathrm{R} \\
\text { ratio }\end{array}$} \\
\hline & & & Shoot & Root & Total & Shoot & Root & Total & & \\
\hline$\overline{1}$ & $6.3 \mathrm{c}^{\mathrm{z}}$ & $29.9 \mathrm{a}$ & $0.289 \mathrm{c}$ & $0.426 \mathrm{a}$ & $0.715 \mathrm{~b}$ & $0.023 \mathrm{a}$ & $0.043 \mathrm{a}$ & $0.066 \mathrm{a}$ & 9.18 & 0.53 \\
\hline 2 & $9.8 \mathrm{a}$ & $20.7 \mathrm{c}$ & $0.433 \mathrm{a}$ & $0.355 \mathrm{~b}$ & $0.788 \mathrm{a}$ & $0.024 \mathrm{a}$ & $0.029 \mathrm{~b}$ & $0.053 \mathrm{~b}$ & 6.67 & 0.81 \\
\hline 3 & $10.5 \mathrm{a}$ & $19.9 \mathrm{c}$ & $0.391 \mathrm{~b}$ & $0.323 \mathrm{c}$ & $0.714 \mathrm{~b}$ & $0.019 \mathrm{~b}$ & $0.025 \mathrm{~b}$ & $0.044 \mathrm{~b}$ & 6.12 & 0.79 \\
\hline 4 & $8.5 \mathrm{~b}$ & $24.2 \mathrm{~b}$ & $0.312 \mathrm{c}$ & $0.303 \mathrm{~d}$ & $0.614 \mathrm{c}$ & $0.018 \mathrm{~b}$ & $0.027 \mathrm{~b}$ & $0.045 \mathrm{~b}$ & 7.29 & 0.64 \\
\hline 5 & $9.9 \mathrm{a}$ & $20.4 \mathrm{c}$ & $0.301 \mathrm{c}$ & $0.323 \mathrm{c}$ & $0.624 \mathrm{c}$ & $0.017 \mathrm{~b}$ & $0.028 \mathrm{~b}$ & $0.045 \mathrm{~b}$ & 7.15 & 0.59 \\
\hline
\end{tabular}

${ }^{\mathrm{z}}$ Means within a column followed by the same letters are not significantly different at the $5 \%$ level of Duncan's multiple range test.

60 red LEDs connected in series. Therefore, light was emitted naturally with $60-\mathrm{Hz}$ frequency and $50 \%$ duty ratio subject to Taiwan's AC system. Treatment 3 used DC power generated from driver with $100 \%$ duty ratio. Treatment 5 also used DC power to generate $60 \mathrm{~Hz}$ frequency and $50 \%$ duty ratio. For treatment 4 , blue LED was added and the $\mathrm{R}$ to $\mathrm{B}$ ratio was maintained at 1.5 , the same as for TFL.

Experimentaldesign and statistical analysis. Plant height, chlorophyll content, fresh and dry weight of shoots and roots were measured for each treatment of 50 samples $28 \mathrm{~d}$ after planting. During each sampling, chlorophyll content of the youngest fully expanded leaf was measured using portable chlorophyll meter(Minolta SPAD 502; Spectrum Technologies). Percentage of dry matter and shoot $(\mathrm{S})$ to root ratio $(\mathrm{R}),(\mathrm{S} / \mathrm{R}$, calculated using dry weight) were also calculated. Data were analyzed using Duncan's multiple range test and orthogonal contrasts using SAS (SAS Inst., Cary, N.C.).

\section{Results and Discussion}

Table 2 showed that providing the same PPF and photoperiod with red + blue light (Treatments 1 and $4, \mathrm{R} / \mathrm{B}=1.5$ ) or red light alone (Treatments 2,3, and 5) caused the differences in Zantedeschia plantlet height, chlorophyll content and total dry weight during 4 weeks of cultivation. TFL treatment had the highest value on dry weight and chlorophyll content and lower plant height than LED treatments. Contrast treatment 1 with others (Tables 4, 5 and 6) also showed the same results. However, within LED treatments, there were no significant difference in dry weight but differences in chlorophyll content and plant height. When blue light was added, shorter plant height and higher chlorophyll content can be found. Orthogonal contrasts also revealed that there were no significant differences on dry weight between LED treatments (Table 6, contrast treatment 4 with 2,3, and 5) but in plant height (Table 4, contrast treatment 4 with 2, 3, and 5 ) and chlorophyll content (Table 5, contrast treatment 4 with 2, 3, and 5). Shorter plant height and higher chlorophyll content can be found in red + blue light cases. It showed that blue light may be involved in plant height and chlorophyll development control. In treatments 1 and $4, \mathrm{R}$ to $\mathrm{B}$ ratios were the same, however, TFL treatment derived shortest plant height, highest chlorophyll content and highest dry weight. Orthogonal contrast treatment 1 with 4 (Tables 4, 5, and 6) revealed same result: not only blue light, but also other wavebands of light are involved in this control.

Table 3. Average tuber size in smallest diameter, size distribution and percentage of marketable tuber size in each treatment after 6 months transplanting in greenhouse.

\begin{tabular}{|c|c|c|c|c|c|}
\hline Treatment & $\begin{array}{l}\text { Tuber } \\
\text { size } \\
(\mathrm{cm})\end{array}$ & $\begin{array}{c}\text { Size } \\
<3 \mathrm{~cm} \\
(\%)\end{array}$ & $\begin{array}{c}\text { Size } \\
3-5 \mathrm{~cm} \\
(\%)\end{array}$ & $\begin{array}{c}\text { Size } \\
>5 \mathrm{~cm} \\
(\%)\end{array}$ & $\begin{array}{c}\text { Marketable } \\
\text { size }^{z} \\
(\%)\end{array}$ \\
\hline$\overline{1}$ & $4.2 \mathrm{a}^{\mathrm{y}}$ & 0.0 & 93.3 & 6.7 & 100.0 \\
\hline 2 & $4.1 \mathrm{a}$ & 0.0 & 96.5 & 3.5 & 100.0 \\
\hline 3 & $4.0 \mathrm{a}$ & 7.1 & 85.8 & 7.1 & 92.9 \\
\hline 4 & $4.5 \mathrm{a}$ & 3.7 & 66.7 & 29.6 & 96.3 \\
\hline 5 & $3.9 \mathrm{a}$ & 7.8 & 79.3 & 12.9 & 92.2 \\
\hline
\end{tabular}

${ }^{\mathrm{z}}$ Marketable size means the smallest diameter of the tuber is $>3 \mathrm{~cm}$.

${ }^{y}$ Means within a column followed by the same letters are not significantly different at the $5 \%$ level of Duncan's multiple range test.

Table 4. Analysis of variance summary for the plant height of Zantedeschia plantlets. Data were analyzed using procedures for a completely randomized design with treatment comparisons made using orthogonal contrasts.

\begin{tabular}{|c|c|c|c|c|}
\hline Source & df & Sums of squares & Mean square & F value \\
\hline Treatment & 5 & 52.192 & 10.439 & $3.21^{* *}$ \\
\hline Error & 54 & 175.369 & 3.247 & \\
\hline Corrected total & 59 & 227.561 & & \\
\hline \multicolumn{5}{|l|}{ Contrasts } \\
\hline Treatment 1 vs. others ${ }^{\mathrm{z}}$ & 1 & 27.421 & 27.421 & $8.44^{* * *}$ \\
\hline Treatment 2 vs. $3^{y}$ & 1 & 3.872 & 3.872 & $1.19^{\mathrm{NS}}$ \\
\hline Treatment 4 vs. 2,3 and $5^{x}$ & 1 & 13.624 & 13.624 & $4.20^{* *}$ \\
\hline Treatment 1 vs. $5^{\mathrm{w}}$ & 1 & 9.112 & 9.112 & $2.81^{\mathrm{NS}}$ \\
\hline Treatment 1 vs. $4^{\mathrm{v}}$ & 1 & 2.964 & 2.964 & $4.91^{* * *}$ \\
\hline Treatment 1 vs. $2^{\mathrm{u}}$ & 1 & 16.381 & 16.381 & $5.04^{* *}$ \\
\hline
\end{tabular}

zTreatment of TFL light alone vs. all other treatments.

yTreatment of red light alone using AC power vs. treatment using DC power.

${ }^{x}$ Treatment of red + blue light vs. red light alone using LED.

wTreatment of $60 \mathrm{~Hz}$ using TFL vs. $60 \mathrm{~Hz}$ using LED.

vTreatment of $\mathrm{R} / \mathrm{B}=1.5$ using TFL vs. using LED.

uTreatment of TFL vs. red LED light alone using AC power.

NS,**N Nonsignificant or significant contrast at the 0.05 level.

Percentage of dry matter and $\mathrm{S}$ to $\mathrm{R}$ ratio of plantlets were different within treatments (Table 2). Treatment 1 had the highest dry matter content (about 9\%), followed by treatments 4 and 5 (about 7\%) and treatments 2 and 3 (about $6 \%$ ) were the worse. Treatment 2 had the highest $\mathrm{S}$ to $\mathrm{R}$ ratio and treatment 1 had the lowest. It seemed that TFL treatment produced more root parts than red light alone using LEDs. Besides red light, others bands of light are needed for root parts development.

In the cases of providing red light alone (Treatments 2,3, and 5), there were no significant differences on plant height, chlorophyll content, dry weight (Table 2) and tuber size (Table 3) no matter how the red light were provided from LEDs. Same results were also revealed on contrast 2 in Tables 4 to 6 . The only difference between treatments 2 and 3 was the driving power. Since one red LED consumed $2 \mathrm{v}$. In total, 60 LEDs were connected in series and powered by AC power with 60 $\mathrm{Hz}$ frequency. The main advantage of using AC powered red LEDs was cost down. Costs on $\mathrm{AC} / \mathrm{DC}$ converter and frequency generator, etc can be removed. Further study is needed to test on the lifetime of LEDs using AC power. Contrast treatment 1 with 5 and treatment 1 with 4 (Tables 5 and 6) showed that there were significant differences between TFL, treatment 2 and treatment 5 in chlorophyll content and dry weight. All treatments had the same frequency of $60 \mathrm{~Hz}$. Treatments 2 and 5 had no differences in plant height, chlorophyll content and dry weight (Table 2). However, differences showed between red LED light alone and TFL. It seemed that not frequency but light quality caused these results.

Results showed that no matter what kind of light provided (TFL or LEDs) or how the current was provided to LEDs (AC or DC), similar tuber size can be produced at the end of growth (first column in Table 3). The influence of light on crops during the in vitro stage does not last to the end of the tuber formation stage. Percentage of marketable size $(>3 \mathrm{~cm})$ tuber was $>90 \%$ in all treatments (Table 3 ).

In conclusion, blue light was one factor on plant height and chlorophyll development control for Zantedeschia plantlets in vitro. 
Table 5. Analysis of variance summary for the chlorophyll content of Zantedeschia plantlets. Data were analyzed using procedures for a completely randomized design with treatment comparisons made using orthogonal contrasts.

\begin{tabular}{|c|c|c|c|c|}
\hline Source & $\mathrm{df}$ & Sums of squares & Mean square & $F$ value \\
\hline Treatment & 5 & 861.274 & 172.255 & $11.27^{* * *}$ \\
\hline Error & 54 & 825.552 & 15.288 & \\
\hline Corrected total & 59 & 1686.826 & & \\
\hline \multicolumn{5}{|l|}{ Contrasts } \\
\hline Treatment 1 vs. others ${ }^{z}$ & 1 & 745.133 & 745.133 & $48.74^{* *}$ \\
\hline Treatment 2 vs. $3^{y}$ & 1 & 28.322 & 28.322 & $1.85^{\mathrm{NS}}$ \\
\hline Treatment 4 vs. 2,3 and $5^{\mathrm{x}}$ & 1 & 77.875 & 77.875 & $15.09^{* * *}$ \\
\hline Treatment 1 vs. $5^{\mathrm{w}}$ & 1 & 587.528 & 587.528 & $38.43^{* * *}$ \\
\hline Treatment 1 vs. $4^{\mathrm{v}}$ & 1 & 242.208 & 242.208 & $15.84^{* *}$ \\
\hline Treatment 1 vs. $2^{\mathrm{u}}$ & 1 & 389.845 & 389.845 & $25.50^{* *}$ \\
\hline
\end{tabular}

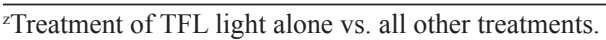

yTreatment of red light alone using AC power vs. treatment using DC power.

xTreatment of red + blue light vs. red light alone using LED.

wTreatment of $60 \mathrm{~Hz}$ using TFL vs. $60 \mathrm{~Hz}$ using LED.

"Treatment of $\mathrm{R} / \mathrm{B}=1.5$ using TFL vs. using LED.

"Treatment of TFL vs. red LED light alone using AC power.

NS, ${ }^{* *}$ Nonsignificant or significant contrast at the 0.05 level.

Table 6. Analysis of variance summary for the dry weight of Zantedeschia plantlets. Data were analyzed using procedures for a completely randomized design with treatment comparisons made using orthogonal contrasts.

\begin{tabular}{lrccr}
\hline Source & df & Sums of squares & Mean square & F value \\
\hline Treatment & 5 & 0.00575 & 0.001151 & $6.47^{* * *}$ \\
Error & 54 & 0.00960 & 0.000177 & \\
Corrected total & 59 & 0.01536 & & \\
Contrasts & & & & \\
$\quad$ Treatment 1 vs. others & & 0.005150 & 0.005150 & $28.94^{* *}$ \\
Treatment 2 vs. 3 & 1 & 0.000055 & 0.000055 & $0.31^{\mathrm{NS}}$ \\
Treatment 4 vs. 2, 3 and 5 & 1 & 0.000016 & 0.000016 & $0.09^{\mathrm{NS}}$ \\
Treatment 1 vs. 5 & 1 & 0.004936 & 0.004936 & $27.74^{\text {w }}$ \\
Treatment 1 vs. 4v & 1 & 0.002813 & 0.002813 & $15.81^{\text {*** }}$ \\
Treatment 1 vs. 2 & 1 & 0.002215 & 0.002215 & $12.45^{* *}$ \\
\hline
\end{tabular}

uTreatment of TFL light alone vs. all other treatments.

${ }^{v}$ Treatment of red light alone using AC power vs. treatment using DC power.

wTreatment of red + blue light vs. red light alone using LED.

${ }^{x}$ Treatment of $60 \mathrm{~Hz}$ using TFL vs. $60 \mathrm{~Hz}$ using LED.

${ }^{y}$ Treatment of $\mathrm{R} / \mathrm{B}=1.5$ using TFL vs. using LED.

${ }^{z}$ Treatment of TFL vs. red LED light alone using AC power.

NS,**Nonsignificant or significant contrast at the 0.05 level.

At present, the cost of blue LEDs can be 10 times more than that of red LEDs. Results of this study showed that growth of Zantedeschia plantlets in vitro using only AC powered red LEDs is feasible. No significant difference can be found after 6 months of tuber formation growth in greenhouse.

\section{Literature Cited}

Appelgren, M. 1991. Effects of light quality on stem elongation of Pelargonium in vitro. Scientia Hort. 45:345-351.

Aksenova, N.P., T. N. Konstantinova, L.I. Sergeeva, I. Machackova, and S.A. Golyanovskaya. 1994. Morphogenesis of potato plants in vitro. I. Effect of light quality and hormones. J. Plant Growth Regulat. 13:143-146.

Brown, C.S., A.C. Schuerger, and J.C. Sager. 1995. Growth and photomorphogenesis of pepper plants under red light-emitting diodes with supplemental blue or far-red lighting. J. Amer. Soc. Hort. Sci. 120:808-813.

Bula, R.J., R.C. Morrow, T.W. Tibbitts, D.J. Barta, R.W. Ignatus, and T.S. Martin. 1991. Lightemitting diodes as a radiation source for plants. HortScience. 26:203-205.

Clemens, J. and T.E. Welsh. 1993. An overview of the New Zealand calla industry, research directions and year-round tuber production. Acta Hort. 337:161-166.

Economou, A.S. and P.E. Read. 1987. Light treat- ments to improve efficiency of in vitro propagation system. HortScience 22(5):751-754.

Fang, W. and R.C. Jao. 2000. A review on artificial lighting of tissue cultures and transplants, $\mathrm{p}$. 108-113. In: C. Kubota and C. Chun (eds.). Transplant production in the 21st century. Kluwer Academic Publishers, The Netherlands.

Iwanami, Y., T. Kozai, Y. Kitaya and S. Kino. 1992. Effects of supplemental red and far-red lighting using light emitting diode on stem elongation and growth of potato plantlets in vitro. p. 183. In: Abstr. Intl. Symp. Transplant Production Sytems. 21-26 July 1992. Yokohama, Japan.

Jao, R.C. and W. Fang. 2003. An adjustable light source for photo-phyto related research and young plant production. Appl. Eng. Agr. 19(5):601-608

Jao, R.C. and W. Fang. 2004a. Effects of frequency and duty ratio on the growth of potato plantlets in vitro using light emitting diodes. HortScience 39(2):375-379.

Jao, R.C. and W. Fang. 2004b. Growth of potato plantlets in vitro is different when provided concurrent versus alternating red and blue light photoperiods. HortScience 39(2):380-382.

Miyashita, Y., T. Kimura, Y. Kitaya, and T. Kozai. 1994. Effects of red light on the growth and morphology of potato plantlets in vitro: Using light emitting diodes (LEDs) as light source for micropropagation. Acta Hort. 418:169-173.

Taiz, L. and E. Zeiger. 1991. Plant physiology, p. 179-264. 1st ed. Benjamin/Cummings Publ. Co., New York. 